\title{
Anaerobic Fungal Mevalonate Pathway Genomic Biases Lead to Heterologous Toxicity Underpredicted by Codon Adaptation Indices
}

\author{
Ethan T. Hillman ${ }^{1,2,+}{ }^{\mathbb{D}}$, Elizabeth M. Frazier ${ }^{1}$, Evan K. Shank ${ }^{3}$, Adrian N. Ortiz-Velez ${ }^{1, \ddagger}$, Jacob A. Englaender ${ }^{1, \S}$ \\ and Kevin V. Solomon $1,2, *, \|$ (iD
}

check for updates

Citation: Hillman, E.T.; Frazier, E.M.; Shank, E.K.; Ortiz-Velez, A.N.;

Englaender, J.A.; Solomon, K.V.

Anaerobic Fungal Mevalonate

Pathway Genomic Biases Lead to

Heterologous Toxicity

Underpredicted by Codon

Adaptation Indices. Microorganisms

2021, 9, 1986. https://doi.org/

10.3390/microorganisms 9091986

Academic Editor: James Chong

Received: 30 August 2021

Accepted: 16 September 2021

Published: 18 September 2021

Publisher's Note: MDPI stays neutral with regard to jurisdictional claims in published maps and institutional affiliations.

Copyright: (c) 2021 by the authors. Licensee MDPI, Basel, Switzerland. This article is an open access article distributed under the terms and conditions of the Creative Commons Attribution (CC BY) license (https:/ / creativecommons.org/licenses/by/ $4.0 /)$.
1 Department of Agricultural and Biological Engineering, Purdue University, West Lafayette, IN 47906, USA; ehillman@umich.edu (E.T.H.); frazie34@purdue.edu (E.M.F.); Aortizvelez7438@sdsu.edu (A.N.O.-V.); jaenglaender@gmail.com (J.A.E.)

2 Purdue University Interdisciplinary Life Sciences, Purdue University, West Lafayette, IN 47906, USA

3 Department of Biological Sciences, Purdue University, West Lafayette, IN 47906, USA; shank3@purdue.edu

* Correspondence: kvs@udel.edu

† Present Address: Department of Internal Medicine, University of Michigan Medical School, Ann Arbor, MI 48109, USA.

$\ddagger$ Present Address: Department of Biology, San Diego State University, San Diego, CA 92182, USA.

$\S \quad$ Present Address: Agrospheres, INC., Charlottesville, VA 22901, USA.

|| Present address: Department of Chemical \& Biomolecular Engineering, University of Delaware, Newark, DE 19716, USA.

Abstract: Anaerobic fungi are emerging biotechnology platforms with genomes rich in biosynthetic potential. Yet, the heterologous expression of their biosynthetic pathways has had limited success in model hosts like E. coli. We find one reason for this is that the genome composition of anaerobic fungi like $P$. indianae are extremely AT-biased with a particular preference for rare and semi-rare AT-rich tRNAs in E coli, which are not explicitly predicted by standard codon adaptation indices (CAI). Native P. indianae genes with these extreme biases create drastic growth defects in E. coli (up to $69 \%$ reduction in growth), which is not seen in genes from other organisms with similar CAIs. However, codon optimization rescues growth, allowing for gene evaluation. In this manner, we demonstrate that anaerobic fungal homologs such as PI.atoB are more active than S. cerevisiae homologs in a hybrid pathway, increasing the production of mevalonate up to $2.5 \mathrm{~g} / \mathrm{L}$ (more than two-fold) and reducing waste carbon to acetate by $~ 90 \%$ under the conditions tested. This work demonstrates the bioproduction potential of anaerobic fungal enzyme homologs and how the analysis of codon utilization enables the study of otherwise difficult to express genes that have applications in biocatalysis and natural product discovery.

Keywords: anaerobic fungi; mevalonate pathway; isoprenoid biosynthesis; heterologous expression; codon usage; codon optimization

\section{Introduction}

Over the last century, fungi have been a source of valuable products in biotechnology, from medicines and insecticides to food additives and enzymes [1]. Anaerobic fungi in particular are increasingly recognized as a vast, untapped source of enzymes for biotechnology [2-4]. Genomic studies of anaerobic fungi show they have the largest array of biomass-degrading enzymes among fungi, which can be used for platforms that convert lignocellulosic waste to biofuels and chemicals $[3,5]$. In addition to plant biomassdegrading enzymes, anaerobic fungi have specialized membrane transporters [6] and unique biosynthetic pathways $[7,8]$ that may be a valuable source of natural products, like polyketides synthases (PKS), non-ribosomal peptide synthetases (NRPS), terpenes, and bacteriocins [1,9]. However, the full potential of anaerobic fungi remains unrealized because there are few existing tools for their engineering. 
Heterologous expression partially addresses this gap by evaluating and using promising genes from hard-to-engineer organisms in more amenable model organisms such as E. coli and S. cerevisiae [10]. These strategies have been used to make products in the food, pharmaceutical, and agricultural industries [11]. While heterologous expression is a very powerful tool, the evaluation of many proteins have been limited by potential pitfalls, such as codon bias [12], post-translation modification [13], and dissimilarity of host environment [14,15], that can cause expression to fail [16]. Previous attempts to heterologously express anaerobic fungal genes have often encountered similar issues in both E. coli and S. cerevisiae $[6,13,17]$. However, E. coli has successfully been used as a host for production of several proteins from anaerobic fungi, including cyclophilins, cellulases, and both hydrogenosomal, and scaffoldin [2,9]. Despite these successes, issues related to the expression of multiple anaerobic fungal proteins or full biosynthetic pathways in E. coli. have not been resolved.

One of the factors that limits the heterologous expression of anaerobic fungal genes in these hosts is that the genome composition of anaerobic fungi is divergent from most model organisms. The genomes of anaerobic fungi have the lowest \%GC in the fungal kingdom ( $20 \%$ GC) and are largely AT-rich in both the intergenic and coding regions [18]. For example, in the recently isolated anaerobic fungus Piromyces indianae, or Piromyces sp. UH3-1 [19,20], the AT-rich regulatory regions of DNA skew the overall \%GC lower, while the coding regions remain relatively AT-biased at around $27.9 \% \mathrm{GC}$. On the other hand, the genomes of the model organisms E. coli and S. cerevisiae are more balanced at around $50 \%$ and $38 \%$ GC, respectively, with little difference between coding and intergenic regions [21,22]. The disparities in gene composition between anaerobic fungi and the underlying codon utilization of model hosts have hindered heterologous expression of anaerobic fungal genes from traditionally cloned genes [13]. The overuse of low abundance codons in model organisms with dissimilar codon usage is anticipated to impact cell health by depleting tRNA pools vital to the expression of essential genes like those involved in cell proliferation [23]. Synthesis of codon-optimized genes enables us to efficiently overcome the barriers that hinder our ability to evaluate and tap the potential of anaerobic fungi with a variety of model yeast and bacterial hosts, including E. coli.

In this study, we evaluated the effects of expressing native and codon optimized genes from anaerobic fungi in E. coli. We focused on expressing individual genes and the complete mevalonate biosynthesis pathway from recently isolated Piromyces indianae, a pathway composed of three genes (atoB, HMGS, and HMGR) that convert acetyl-CoA into mevalonate, a valuable terpenoid precursor. We demonstrate that, without codon optimization, some genes from anaerobic fungi cause moderate to severe growth defects in E. coli that are not predicted by the standard codon adaptation index. Additionally, these defects are evident even in strains designed to express difficult genes composed of rare E. coli codons. Further, we provide evidence that codon optimization enables E. coli to produce compounds from the biosynthesis pathways of anaerobic fungi, and that specific $P$. indianae homologs increased production approximately 2.5 -fold compared to the heterologous pathway with canonical yeast homologs from $S$. cerevisiae. While further optimization of these homologs may be achieved by exchanging promoters of different strength, the work demonstrated here provides a rationale for revisiting anaerobic fungal enzymes that previously failed to heterologously express in order to fully evaluate their biotechnological capacity for biofuels and bioproduction.

\section{Materials and Methods}

\subsection{Homolog Identification, Primer Design, PCR, RT-PCR, and Cloning}

Using the Search terms "acetoacetyl-CoA transferase", "hydroxymethylglutryl-CoA synthetase", and "hydroxymethylglutryl-CoA reductase,"the genomic databse of Neocallimastgomycota on Mycocosm [24] was searched. The coding regions of the resulting protein sequences were analyzed with BLAST [25] to confirm homologs. The coding sequence of the homologs were obtained from Mycocosm and aligned using MEGA7 [26]. Degenerate 
primers were designed to amplify the gene sequences from Piromyces indianae (Piromyces sp. UH3-1) [19]. PCR amplicons were sequenced to confirm target identity of the atoB, HMGS, or HMGR homolog. To isolate genes without introns for cloning, genes were amplified from a cDNA library. Total RNA was extracted from Piromyces indianae using the QIAGEN (Germantown, MD, USA) AllPrep Fungal DNA/RNA/Protein kit. Reverse transcription PCR was performed using the QIAGEN QuantiTect Reverse Transcription Kit along with random octamers according to the manufacturer's instructions. From the resulting cDNA pool, the target genes were PCR amplified with primers flanked by a $5^{\prime}$ BglII or XmaI site and a $3^{\prime}$ XhoI, BcuI, or NotI site (Table S4). Finally, these amplicons were digested with the flanking enzymes and ligated with Rapid T4 ligase (ThermoFisher; Waltham, MA, USA) into the pETM6 backbone [27] digested with the same enzymes and dephosphorylated with calf intestinal alkaline phosphatase (CIAP). Plasmids were transformed by heat shock into chemically competent DH5 E. coli cells (Table S5) and plasmids were subsequently isolated and sequenced to confirm the constructs were correct. Following the ePathBrick [27] design, the full pathway was constructed on the backbone by first joining the ato $B$ and HMGS homolog in one round of cloning, and joining the HMGR homolog with the first two genes in a final step. The analogous yeast pathway [28] was obtained from Addgene as a benchmark. In a manner similar to the original construction of the pathway, combinations of the yeast and Piromyces homologs were made to assess the individual productivities of the various homologs. Similarly, vectors with weaker or stronger T7 promoter derivates were generated and combined in an attempt to enhance mevalonate production. Because a yeast homolog vector organized with the $a t o B_{\mathrm{H} 9} \_H M G S_{\mathrm{C} 4}{ }_{H} H G R_{\mathrm{H} 9}$ pathway was found to be a high-producing stain, the Piromyces homolog pathways were constructed to match this promoter structure. All gene sequences and plasmids used in this study are listed in Tables S6 and S7, respectively.

\subsection{Growth Analysis}

Vectors containing the homologs for the PI.atoB, PI.HMGS, or PI.HMGR gene were each transformed into an electrocompetent BL21 (DE3) E. coli strain for expression from the T7 promoter (Invitrogen; Waltham, MA, USA). Full and intermediate pathway vectors were transformed similarly. Overnight starter cultures were inoculated from single colonies and used to inoculate fresh LB/ampicillin $5 \mathrm{~mL}$ cultures to OD 0.05 the following day. The initial O.D. was adjusted to approximately 0.05 and IPTG was added to $100 \mu \mathrm{M}$ at the time of inoculation. Cultures were grown at $37^{\circ} \mathrm{C}$ while shaking at $250 \mathrm{rpm}$ in parallel with uninduced cultures for approximately three hours with the O.D. being measured every 30 min on a NanoPhotometer ${ }^{\circledR}$ NP80 (Implen; Westlake Village, CA, USA). Percent relative growth was calculated by taking the final $\mathrm{OD}_{600}$ of the induced gene and dividing it by the final $\mathrm{OD}_{600}$ of the uninduced gene across the three-hour experiment. E. coli BL21 CodonPlus (DE3) RIPL strains (Invitrogen, Waltham, MA), which carry additional tRNA for arginine, isoleucine, proline, and leucine, were also transformed and grown in the same manner as described above, with the addition of chloramphenicol $(50 \mu \mathrm{g} / \mathrm{mL})$ in accordance with the $\mathrm{CmR}$ marker on the RIPL vector. All growth experiments were carried out in triplicate with the mean and standard deviation plotted.

\subsection{Codon Adaptation Index, Codon Usage, and Codon Optimization}

The protein encoding sequences were downloaded for E. coli (GenBank Accession \#: U00096.3) and P. indianae genomes (Mycocosm: piromy1, https:/ / genome.jgi.doe.gov / portal/Piromy1/, accessed on 14 March 2021). Using a python package developed by Lee et al. (2018), the CAI of the E. coli genome and P. indianae genomes were calculated from the coding sequences. The CAI histograms and the Gaussian distribution fit were calculated with PRISM v9.0. To calculate the codon usages, a BioPython [29] script was used to split the coding sequences every three base pairs to create trinucleotide codons for every gene. The codon occurrences were tallied and frequencies were calculated with respect to all trinucleotides ("overall usage") and those that code for the same amino 
acid ("relative usage"). Trinucleotide frequencies, or codon usages, were compared for relative and overall usage between E. coli and P. indianae. Additionally, the codon usage of $E$. coli was used to determine the codon frequencies that should be used for optimizing $P$. indianae genes. The python script written for this analysis was uploaded to https: //github.com/ehillman26/CodonAnalysisForAnaerobicFungi. These gene sequences were manually optimized by removing any rare codons and replacing both rare and infrequently used codons with frequently used codons so that the overall codon frequency of each gene roughly matched the E. coli relative codon usage. Genes were then synthesized by Twist Biosciences and cloned into the PETM6 vector as described above (see Section 2.1). CAI distributions and codon usage data were analyzed and plotted with GraphPad Prism v9.0.0.

\subsection{Mevalonate Production Cultures and HPLC Analysis}

Overnight cultures of BL21 (DE3) strains containing variants of the yeast, Piromyces, or hybrid mevalonate pathways were grown in $\mathrm{LB} / \mathrm{amp}$ at $37^{\circ} \mathrm{C}$. For mevalonate production, cultures were inoculated to an O.D. of 0.05 in $2 Y T$ media $(16 \mathrm{~g} / \mathrm{L}$ tryptone, $10 \mathrm{~g} / \mathrm{L}$ yeast extract, $5 \mathrm{~g} / \mathrm{L} \mathrm{NaCl}, 1 \%$ glycerol; $\mathrm{pH} 7.5)$. Then, small-scale (5 mL) 2YT cultures were grown at $37{ }^{\circ} \mathrm{C}$ while shaking at $250 \mathrm{rpm}$. When cultures reached an O.D. of 1 , they were induced to a final concentration of $500 \mu \mathrm{M}$ IPTG and left overnight (Total 18 h). Final O.D. was measured, and $450 \mu \mathrm{L}$ of cleared supernatant was mixed with $50 \mu \mathrm{L}$ of $14 \% \mathrm{H}_{2} \mathrm{SO}_{4}$ in order to convert produced mevalonate to mevalolactone for HPLC analysis [30]. The acidified supernatant was immediately chilled at $4{ }^{\circ} \mathrm{C}$ for a minimum of $1 \mathrm{~h}$ and analyzed by HPLC. Briefly, analysis of a $20 \mu \mathrm{L}$ sample of the resulting supernatant was injected on an Agilent 1260 instrument with separation via a BioRad Aminex $\mathrm{HPX}-87 \mathrm{H}$ at $50{ }^{\circ} \mathrm{C}$ in $5 \mathrm{mM}$ $\mathrm{H}_{2} \mathrm{SO}_{4}$ mobile phase (rate $0.600 \mathrm{~mL} / \mathrm{min}$ ). Detection was performed with a refractive index detector (RID) in (+) signal polarity mode at $45^{\circ} \mathrm{C}$. To evaluate mevalonate production at larger scales with better aeration, larger 2YT cultures $(50 \mathrm{~mL})$ were also grown under the same parameters as above but in baffled flasks. All mevalonate titer experiments were carried out in triplicate with the mean and standard deviation plotted.

\section{Results and Discussion}

\subsection{Codon Usage and Preferences of P. indianae Are Strongly AT-Biased}

The codon adaptation index (CAI) metric evaluates the potential expression level of a target gene based on its codon usage compared to that of highly expressed genes in the host of interest [31,32]. The CAI of every P. indianae gene using E. coli as the host was evaluated with a publicly available expression dataset [32], and the majority of $P$. indianae genes ( $>98 \%$ ) were found to have E. coli CAI scores under 0.50 (Figure 1 ). The mean and median CAI of $P$. indianae genes are close to 0.35 and 0.34 (Figure 1), respectively, which is about $30 \%$ lower than the mean and median CAI of the E. coli genome ( 0.50). In E. coli, highly expressed genes have a CAI of $\sim 0.7$ reflecting an optimal distribution of rare and abundant codons that does not overly deplete any individual tRNA pool. Moreover, rare codons have a functional role in protein elongation rates and folding. Thus, the exclusive use of abundant codons may be deleterious [33]. Given the low E. coil CAI of P. indianae genes, these genes are not likely to be highly expressed in E. coli [34]. It is not surprising to see that the mean and median of the E. coli genome are close to 0.50 given that its genome and codon usage are largely balanced ( 50\% GC) [21] and the distribution is a normal Gaussian distribution as seen across most genomes [35]. The $P$. indianae distribution is also relatively normal but has a left-skewed mean with lower standard deviation, suggesting it is strongly biased relative to E. coli. Furthermore, there are only ten $P$. indianae genes with a CAI of 0.60 or higher with the maximum CAI around 0.77 . However, with the exception of two genes (ribosomal protein S29 and thioredoxin 2), these genes remain unannotated, hypothetical proteins, with no evidence for their evolutionary origins or function as determined by BLAST. While we can see most genes use different codons (Figure 1), the specific codons that are over- or under-utilized cannot be determined by CAI. 

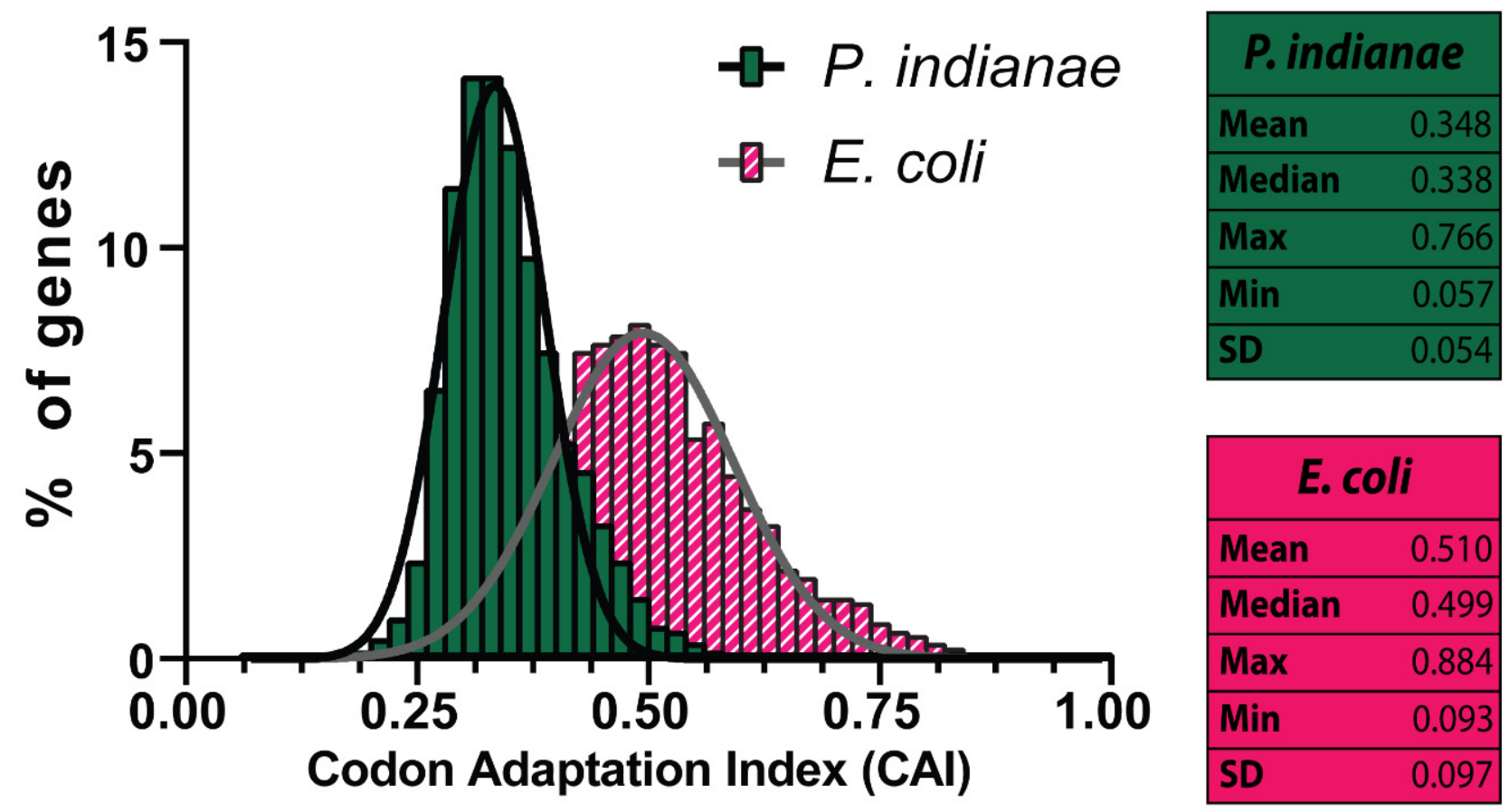

Figure 1. Distribution of Codon adaptation index (CAI) scores for P. indianae and E. coli genes with respect to their fitness in E. coli. Mean, median, maximum, and minimum scores are reported for the distributions. Normal Gaussian distributions are shown for each. $\mathrm{SD}=$ standard deviation.

To further explore what makes P. indianae genes poor fits for E. coli, we evaluated the relative codon usage for each amino and overall codon usage across the genome of P. indianae. The relative codon usage measures the preferred codon for an amino acid in an organism and is the frequency at which a particular codon is used relative to synonymous codons [33]. The overall usage, on the other hand, is the frequency at which a codon is used with respect to the codons for all amino acids. While E. coli uses a variety of AT-rich and GC-rich codons [21], anaerobic fungi are heavily biased towards AT-rich codons [18]. Our comparison of the relative usage of E. coli and P. indianae found that both species only preferred five codons in common out of the 18 amino acids with more than one codon (Figure 2); S. cerevisiae whose genome is somewhat AT-rich ( $39 \%$ GC) and E. coli, in contrast, share eight of the same 18 preferred codons. The largest difference in preferred codons were for asparagine $(\mathrm{Q})$, aspartate $(\mathrm{N})$, arginine $(\mathrm{R})$, proline $(\mathrm{P})$, cysteine $(\mathrm{C})$ and leucine $(\mathrm{L})$ where codon usage of the $P$. indianae codon increased $>40 \%$ compared to the frequency that $E$. coli uses this codon. In all cases, these biases reflect a preference for more AT-rich codons over GC alternatives favored by E. coli.

In addition to differences in synonymous codon preference, codon usage rates for preferred codons were markedly higher in $P$. indianae. Codon use was heavily biased towards use of the preferred codon in P. indianae $83+/-8 \%$ of the time. In contrast, E. coli and S. cerevisiae balance their usage of preferred codons at $57+/-9 \%$ and $58+/-8 \%$ of the time, respectively (Tables S1-S3). Unlike E. coli and other prokaryotes that compartmentalize codon usage using specific codons preferentially for highly expressed genes and other codons for specific processes such as cell division $[23,31,35]$, anaerobic fungal codon usage is uniform across genes regardless of expression level, as is common among eukaryotes (data not shown). Thus, these biases suggest that anaerobic fungi more heavily prefer specific codons whose use is not correlated with expression level. 



Figure 2. Relative and overall codon usage of $P$. indianae compared to E. coli. (A) Ratios of $P$. indianae's codon usage relative to codons for the same amino acids compared to E. coli. (B) Ratios of $P$. indianae's overall codon usage relative to all codons compared to E. coli. Ratios below 1 are shown in pink to indicate codons used more frequently in E. coli than P. indianae; ratios above 1 are shown in green to indicate codons used more frequently by $P$. indianae than $E$. coli. The vertical black dashed lines mark the 2 -fold increase or decrease in codon use compared to E. coli. * and \# indicate E. coli codons that are rare $(\leq 0.5 \%$ overall usage) and semi-rare ( $\leq 1.0 \%$ overall usage), respectively. Delineations between codons encoding different amino acids are indicated by horizontal dashed gray lines.

Anaerobic fungal codon biases are not limited to synonymous codon preferences. $P$. indianae genes overused 13 of the 61 amino-acid-calling codons compared to their overall usage in E. coli (>2-fold increase in the overall codon usage; Figure 2), which is similar to $S$. cerevisiae (14 overused codons compared to E. coli). Not surprisingly, these codons were all AT-rich. Out of these 13 codons, two are rare E. coli codons $\left(\mathrm{AGA}_{\mathrm{R}}\right.$ and $\mathrm{AUA} \mathrm{A}_{\mathrm{I}}$; used in less than $0.5 \%$ of all codons) and two are semi-rare (UCA and $A G U_{S}$; used in less than $1 \%$ of all codons). Frequent use of rare codons is problematic for expression in 
E. coli because it stalls translation and can lead to misfolded or truncated proteins [33]. Because these rare codons also have a special function in regulating the rate of protein synthesis and nascent chain folding [23,36], we suspect that over-expressed genes that consume the already small pools of rare codons could potentially tax the cells and slow down translation, and ultimately growth [37]. The most overused codons, $\mathrm{AAU}_{\mathrm{N}}, \mathrm{UUA}_{\mathrm{L}}$, and $\mathrm{AAA}_{\mathrm{K}}$, however, are not rare codons. Collectively, they are overall used $18.9 \%$ of the time in P. indianae compared to $6.4 \%$ of the time in E. coli (Tables S1 and S2) and demonstrate there are also large differences in non-rare codon preferences. Work prior to this has demonstrated that tRNA pools of abundant codons increase with growth to help maximize cell health while the pools of non-abundant codons remain unchanged $[38,39]$. Much less work has been done to investigate how the overuse of non-abundant codons affects cell physiology [40]. However, it was previously shown that the overexpression of the tnaC gene from $E$. coli that contained semi-rare $C C U_{P}$ codon lead to growth inhibition due to depleted CCU tRNA pools [41]. The genes of $P$. indianae are intriguing case studies because over a dozen of these codons are heavily used here. Overall, $P$. indianae genes use codons that are AT-rich and less frequent in E. coli and could potentially create translational burdens in heterologous hosts when overexpressed.

\subsection{E.coli Are Not Well Equipped to Express the AT-rich Genes of P. indianae}

To test the effects of expressing $P$. indianae genes in $E$. coli, we separately expressed three genes from a biosynthetic pathway from $P$. indianae (Figure $3 \mathrm{~A}$ ). We selected to study the mevalonate pathway ( $a t o B, H M G S$, and HMGR) as this is both a conserved pathway in fungi and because it can be used to support a broad range of isoprenoid bioproduction platforms [42]. Because this mevalonate pathway is not native to most bacteria including E. coli, characterization of these enzymes in this heterologous platform avoids substrate competition between the native pathways in model yeast hosts. Expression of these genes was compared to homologs from S. cerevisiae and E. coli, which have previously been expressed in E. coli [28]. Interestingly, the expression of PI.atoB and PI.HMGS reduced the growth of E. coli by about $69 \%$ and $53 \%$, respectively (Figure 4 ), while expression of PI.HMGR had no effect on growth. These growth defects are unlikely to be the result of enzymatic activity because overexpressing the corresponding homologs from $E$. coli and S. cerevisiae (EC.atoB, SC.HMGS, SC.HMGR) does not result in similar growth reduction compared to the uninduced controls. The standard CAI metric also does not explain this discrepancy, as yeast homologs do not reduce growth despite having similar CAIs to those from P. indianae (Figure 3B).

Interestingly, we see that the HMGR homologs are nearly identical in both number of overused rare codons and their overall usage, and they both result in similar growth effects (Figure 4A). However, PI.atoB and PI.HMGS each only use two rare codons between $3-5 \%$ of the time, yet they have the largest effects on growth (Figure $4 \mathrm{~A}$ ) compared to SC.HMGS, SC.HMGR, and PI.HMGR that have three or more rare codons. Based solely on rare codons, it appears that fewer rare codons results in larger growth deficiencies for these genes. We suspect that the use of additional rare-codons may play a role in slowing down or stalling the translational machinery [33], which in turn slows the drain of the various overused tRNA pools, and thus limits growth defects. Additionally, codon content was recently shown to correlate with the mRNA levels where rare-codons could reduce protein expression by decreasing the stability of mRNA [40]. The $\mathrm{AUA}_{\mathrm{I}}$ codon specifically was shown to have the largest effect at attenuating protein expression, and thus may play a role here in decreasing the lifespan of mRNA that overuse it, namely SC.HMGS, SC.HMGR, and PI.HMGR. In this case, even though these genes have the potential to overuse rare and semi-rare codons, the reduced mRNA levels keep the tRNA pools from being drained as quickly. In either case, it would seem that the overexpression of these proteins affects the physiology of the cell, which agrees with recent global proteomic analysis when proteins are overexpressed [43]. 


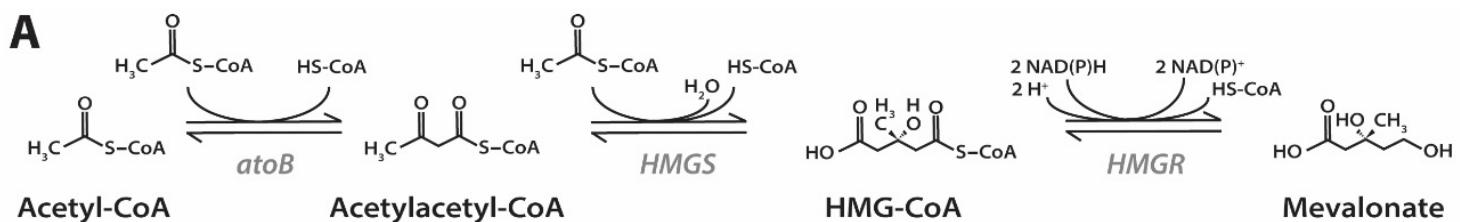

\begin{tabular}{|c|c|c|c|c|c|c|c|c|}
\hline 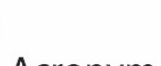 & & & & & & Over & used codo & \\
\hline Acronym & Origin & Gene & E.C. \# & Size & CAl & Rare & Sem & i-rare \\
\hline EC.atoB & E. coli & ato $B$ & 2.3.1.9 & $1.2 \mathrm{~kb}$ & 0.482 & $\operatorname{CCC}_{p}(1.02 \%)$ & $A G U_{s}(1.78 \%)$ & \\
\hline SC.HMGS & S. cerevisiae & HMGS & 2.3.3.10 & $1.4 \mathrm{~kb}$ & 0.452 & $\begin{array}{l}\mathrm{AUA}_{\mathrm{R}}(\mathbf{4 . 4 2} \%) \\
\operatorname{CCC}_{\mathrm{p}}(1.99 \%)\end{array}$ & $\begin{array}{l}\mathrm{AGG}_{\mathrm{R}}(5.96 \%) \\
\mathrm{CGG}_{\mathrm{R}}(2.87 \%)\end{array}$ & $U U A_{L}(3.53 \%)$ \\
\hline SC.tHMGR & S. cerevisiae & $t H M G R$ & 1.1.1.34 & $1.5 \mathrm{~kb}$ & 0.360 & $\begin{array}{l}\operatorname{AGA}_{\mathrm{R}}(2.15 \%) \\
\mathrm{UGU}_{\mathrm{C}}(0.98 \%) \\
\text { AUA }_{1}(1.59 \%)\end{array}$ & $\begin{array}{l}C C U_{p}(1.99 \%) \\
C C A_{p}(1.59 \%) \\
A G U_{S}(1.79 \%)\end{array}$ & $\begin{array}{l}U U A_{L}(4.38 \%) \\
U C A_{S}(1.59 \%) \\
U C C_{S}(1.99 \%)\end{array}$ \\
\hline Pl.atoB & P. indianae & ato $B$ & 2.3.1.9 & $1.2 \mathrm{~kb}$ & 0.469 & $\begin{array}{l}\operatorname{AGA}_{\mathrm{R}}(1.67 \%) \\
\operatorname{UGU}_{\mathrm{C}}(1.67 \%)\end{array}$ & $\begin{array}{l}U \cup A_{L}(4.06 \%) \\
C C A_{p}(4.06 \%)\end{array}$ & $\operatorname{CUU}_{L}(2.86 \%)$ \\
\hline PI.HMGS & P. indianae & HMGS & 2.3.3.10 & $1.3 \mathrm{~kb}$ & 0.465 & $\begin{array}{l}\operatorname{AGA}_{\mathrm{R}}(2.80 \%) \\
\operatorname{UGU}_{\mathrm{C}}(1.94 \%)\end{array}$ & $\begin{array}{l}U \cup A_{L}(5.38 \%) \\
C C A_{p}(3.44 \%)\end{array}$ & \\
\hline PI.HMGR & P. indianae & $H M G R$ & 1.1.1.88 & $3.1 \mathrm{~kb}$ & 0.370 & $\begin{array}{l}\text { AGA }_{\mathrm{R}}(2.15 \%) \\
\text { UGU }_{\mathrm{C}}(0.98 \%) \\
\text { AUA, }_{1}(1.17 \%)\end{array}$ & $\begin{array}{l}U U A_{L}(5.47 \%) \\
A G U_{S}(1.98 \%) \\
C C A_{p}(4.39 \%)\end{array}$ & $\begin{array}{l}C U U_{L}(2.15 \%) \\
U C A_{S}(3.61 \%)\end{array}$ \\
\hline
\end{tabular}

Figure 3. Mevalonate pathway and gene information. (A) Mevalonate biosynthesis pathway showing genes, cofactors, and substrate. (B) Homolog information for the genes evaluated in this study. Overused codons are used 2-fold or more in these genes compared to the host utilization. Rare and semi-rare codons are used $0.5 \%$ and $1.0 \%$ of the time or less, respectively. Overall codon usage of each gene is shown next to the codon. Gene names: acetyl-CoA acetyltransferase (atoB), HMG-CoA synthase (HMGS), and HMG-CoA reductase (HMGR).

A

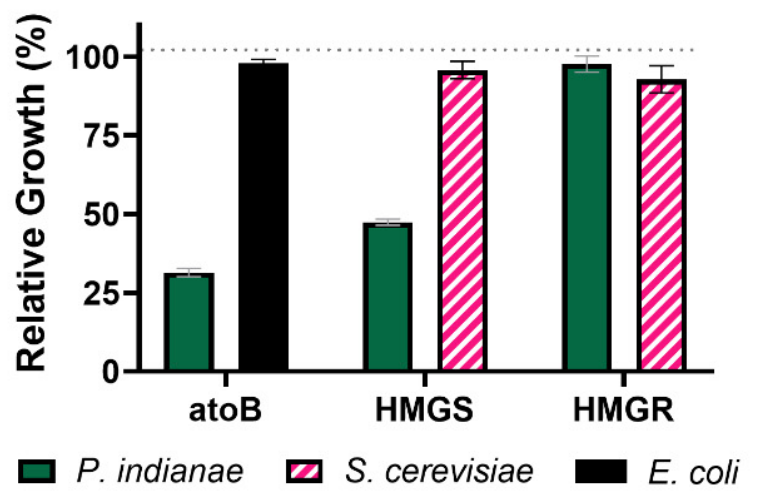

B

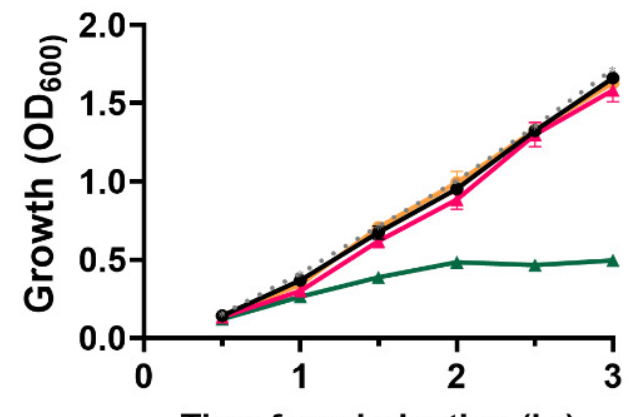

Time from induction (hr)

$\rightarrow \mathrm{PI}$.atoB $(\mathrm{H} 9)$ uninduced $\_\mathrm{PI}$.atoB $(\mathrm{T} 7)$ uninduced

$\rightarrow$ Pl.atoB $(\mathrm{H} 9)$ induced $\quad-$ Pl.atoB $(\mathrm{T} 7)$ induced

Figure 4. Relative growth of E. coli expressing the E. coli, S. cerevisiae, or P. indianae homologs. (A) Relative growth of E. coli BL21 when expressing individual genes of the mevalonate pathway under an inducible T7 promoter. (B) Growth curve of E.coli BL21 expressing the PI.atoB under the T7 promoter and a weaker H9 promoter variant. Growth is relativized to the growth of an uninduced control for each homolog. Relative growth is calculated by taking the final $\mathrm{OD}_{600}$ of the induced gene divided by the final $\mathrm{OD}_{600}$ of the uninduced gene. The T7-mCherry expression control is indicated by a dotted gray line in both panels A \& B. Error bars represent standard deviation; $\mathrm{n}=3$ for all conditions.

This translational burden and growth defect can be alleviated somewhat by reducing promoter strength from a stronger T7 promoter to a weaker H9 variant [27]. Only induction with a strong T7 promoter results in a growth defect (Figure 4B). However, it should be noted that, regardless of the promoter, expression of the native $P$. indianae genes was not detectable via SDS-PAGE (Figure S1), suggesting that both strong and weak promoters resulted in weak or no expression. Growth defects have been similarly observed when cellulases from anaerobic fungi were expressed in S. cerevisiae [13], which may be the result 
of similar codon deficiencies. No defect was seen from inducing the mCherry fluorescent protein with a T7-promoter (dotted gray line, Figure 4A,B). Our work suggests that these deficiencies may be overcome with contemporary codon optimization/harmonization strategies and thus previously examined anaerobic fungal enzymes with negligible expression may need to be reevaluated. Regardless, CAI alone is insufficient to predict heterologous growth defects of anaerobic fungal enzymes due to their severe biases for rare AT-rich codons that E. coli cannot accommodate.

\subsection{Strains with Additional tRNAs for Rare Codons Do Not Effectively Relieve the Burden of Expressing P. indianae Genes}

Strains of E. coli have been created to allow expression of proteins with codon mismatches by adding additional copies of rare tRNA genes. We evaluated if one of these strains, BL21-CodonPlus (DE3) RIPL (Agilent Technologies), that provides an additional tRNA copy for $\mathrm{AGA}_{\mathrm{R}}, \mathrm{AUA}_{\mathrm{I}}, \mathrm{CCC}_{\mathrm{P}}$, and $\mathrm{CUA}_{\mathrm{L}}$, could alleviate the growth defects of $P$. indianae homolog expression. Like other prokaryotes., the tRNA gene copy number and codon usage are highly correlated in the E. coli genome, ultimately allowing them to use codons with more abundant tRNAs at higher rates $[33,44]$. Therefore, increasing the available tRNA pools with additional copies of rare codons tRNA genes may allow increased expression of these genes where it was previously hindered. In this strain, the effect on PI.HMGS growth improved markedly, where growth was only reduced by about $16 \%$. However, the PI.atoB homolog still reduced the growth about by 57\% (Figure 5A). Looking at the specific codons supplemented by this strain, only $A_{G} A_{R}$ is highly used in these $P$. indianae homologs and makes up $1.7 \%$ and $2.8 \%$ of the overall codon usage for $a t o B$ and HMGS, respectively (Figure 3B). Because the other RIPL codons that are supplemented $\left(\mathrm{AUA}_{\mathrm{I}}, \mathrm{CCC}_{\mathrm{P}}\right.$, and $\left.\mathrm{CUA} \mathrm{L}_{\mathrm{L}}\right)$ do not alleviate the drain on the other overused codons, such as $\mathrm{AAU}_{\mathrm{N}}, \mathrm{AAA}_{\mathrm{K}}$, and $\mathrm{UUA}_{\mathrm{L}}$, this strain is ill-equipped to efficiently express the $P$. indianae homologs and growth is still hindered.

A

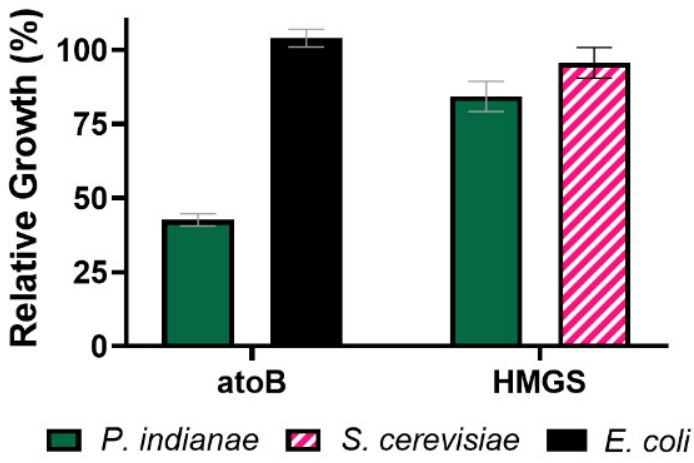

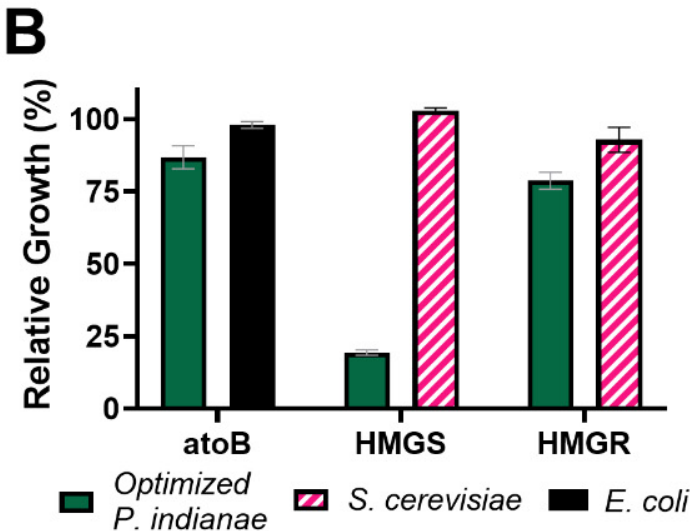

Figure 5. Relative growth in additional strains or with optimized genes. (A) Relative growth of E.coli BL21 ${ }^{+}$RIPL expressing the E. coli, S. cerevisiae, or P. indianae homologs of the mevalonate pathway. (B) Relative growth of E. coli BL21 expressing the $E$. coli-codon optimized versions of the $P$. indianae genes compared to the respective atoB, HMGS, or HMGR homolog. Relative growth is calculated by taking the final $\mathrm{OD}_{600}$ of the induced gene divided by the final $\mathrm{OD}_{600}$ of the uninduced gene. Error bars represent standard deviation; $\mathrm{n}=3$ for all conditions.

\subsection{Codon Optimization Alleviates the Growth Deficiencies Seen When the P. indianae atoB Is} Expressed in E. coli

Because accommodating all of the codon deficiencies would require a large plasmid or an extensive strain engineering undertaking, we selected a codon harmonization approach to resolve the majority of the underlying codon issues. Codon harmonization matches the codon usage of each gene of interest to that of the E. coli genome to ensure proper protein folding and avoid potential stresses related to overusing any one codon-a strategy which is optimal for bacterial hosts [45]. When the codon optimized P. indianae 
homologs were expressed, we saw that the PI.atoB and PI.HMGR homologs had minor growth defects, growing to roughly $80 \%$ of the control level (Figure $5 B$ ). This suggests that by reducing the usage of suboptimal codons, $P$. indianae genes can be expressed without the same detrimental growth defects seen from the native unoptimized genes. Similarly, SDS-PAGE analysis demonstrates that the codon optimized genes express much better than the unoptimized genes (Figure S1). However, the growth defect of PI.HMGS observed after optimization was nearly twice as severe compared to the unoptimized gene. We suspected that at least part of the growth defect seen here is a result of increased protein activity when PI.HMGS in combination with the native E. coli atoB produce a toxic intermediate, hydroxy $\beta$-methylglutaryl-CoA (HMG-CoA), from acetyl-CoA pools [42,46]. The unoptimized PI.HMGS, however, does not produce this toxic effect possibly due to lower expression (Figure S1). As seen by another group expressing optimized genes from anaerobic fungi in E.coli [6], the growth deficiency may also result from improper folding or membrane incorporation. However, predictors of transmembrane domains [47] did not reveal the presence of any membrane-associated domains within PI.HMGS unlike the native S. cerevisiae homolog, which was previously truncated for expression in E. coli [28]. When the PI.HMGS gene was expressed as part of the complete pathway, we did not observe this same growth defect (see growth data, Figure S2) suggesting that the toxic HMG-CoA was being converted into mevalonate (see Section 3.6).

\subsection{Expression of Unoptimized Genes Hinders Biosynthesis from P. indianae Genes}

Despite the low CAI scores of the yeast homologs, expressing them in E. coli can produce mevalonate and subsequently terpenoids [28]. Initially, we evaluated the native mevalonate pathways (Figure 3A) of S. cerevisiae, P. indianae, and a hybrid of the two (Figure 6A) in order to understand if the native genes could produce mevalonate despite being poorly adapted for the $E$. coli chassis. To create the pathways, we took the individually cloned genes and combined them into one plasmid using the ePathBrick system [27]. In contrast to previous approaches that use an operonic approach to express all genes under one T7 promoter $[28,48]$, we expressed each gene at independent levels via separate T7-inducible promoters of varying strength [49]. This also enabled the investigation of how changing the expression level of each enzyme with different promoter strengths affected the mevalonate output (see Figure $6 \mathrm{~A}$ ). We found that a common library variant with a ato $B_{\mathrm{H} 9}-H M G S_{\mathrm{C} 4}-H M G R_{\mathrm{H} 9}$, or $\mathrm{H} 9-\mathrm{C} 4-\mathrm{H} 9$, promoter architecture improved titers three-fold to $\sim 1.0 \mathrm{~g} / \mathrm{L}$ relative to initial reports with a T7 operon [28] (Figure 6B). The promoter strength of $\mathrm{H} 9$ is $\sim 30 \%$ that of the consensus $\mathrm{T} 7$ promoter while $\mathrm{C} 4$ is a stronger promoter ( $150 \%$ of consensus) [49]. In contrast to the yeast pathway, the native P. indianae pathway did not produce noteworthy amounts of mevalonate $(<0.10 \mathrm{~g} / \mathrm{L})$ under either the all T7 or H9-C4-H9 promoter configuration (Figure 6A). While the low yields with the native $P$. indianae homologs are not surprising given the associated growth deficiencies of individual genes, the growth defects are only marginal when the genes are expressed together in the H9-C4-H9 configuration. The growth of the native pathway is similar to the pathway consisting of the codon optimized P. indianae homologs (Figure S2). As PI.HMGR expression was not associated with any growth defect in E. coli, we swapped this homolog for the SC.HMGR variant in the all yeast pathway and evaluated whether a hybrid of the yeast and P. indianae pathway (EC.atoB-SC.HMGS-PI.HMGR) could produce any mevalonate. Interestingly, we found that this hybrid pathway produced mevalonate titers similar to the yeast pathway under the T7 promoters (Figure 6B). Though the titers are not as high as the H9-C4-H9 yeast pathway that it was derived from, the production of even $0.25 \mathrm{~g} / \mathrm{L}$ mevalonate is encouraging given that this gene was not codon optimized and came directly from $P$. indianae. Therefore, we evaluated pathways with codon optimized $P$. indianae homologs as a case study for how biosynthetic pathways from anaerobic fungi can be evaluated in E. coli for the discovery and production of valuable metabolites. 
A
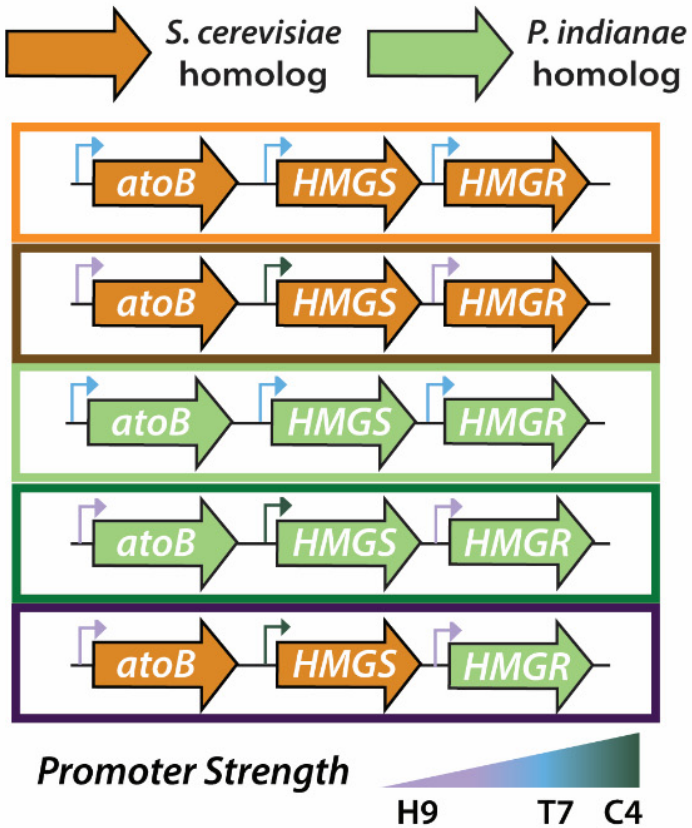

B

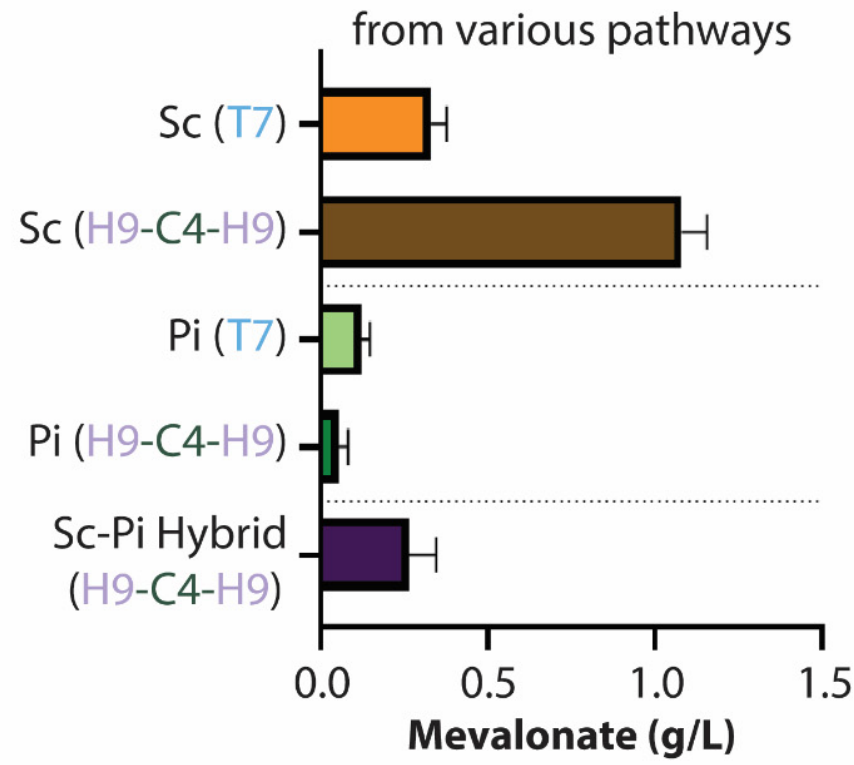

Figure 6. Mevalonate pathway variants and titers with unoptimized genes. (A) Different promoter and gene configurations of the Martin et al. (orange) and P. indianae (green) mevalonate pathways and a hybrid of them. (B) Mevalonate titers for the pathway variants after $20 \mathrm{~h}$ of culture; $\mathrm{Sc}=$ yeast, $\mathrm{Pi}=$ P. indianae; $\mathrm{T} 7=\mathrm{T} 7$ promoters for each, $\mathrm{H} 9=\mathrm{H} 9-\mathrm{C} 4-\mathrm{H} 9 \mathrm{promoter}$ configuration as shown in panel A. Error bars represent standard deviation; $n=3$ for all conditions.

\subsection{Codon Optimization Allows Heterologous Production of Mevalonate from P. indianae Enzymes}

Because codon optimization of the $P$. indianae genes relieved the growth deficiencies of the $a t o B$ gene, we evaluated if it also enabled increased production of mevalonate. Specifically, we investigated the production of the $P$. indianae pathway with both native and codon optimized genes, the yeast pathway, and hybrids thereof. In addition to mevalonate production, we also tracked the produced acetate to compare how these constructs affected the flux of the acetyl-CoA precursor to mevalonate or acetate. Hybrid pathways of yeast and $P$. indianae codon optimized genes were able to increase titers almost two-fold suggesting that codon optimized P. indianae homologs of the mevalonate pathway may be more catalytically active than yeast variants (Figure 7). In particular, PI.atoB improved mevalonate production by shunting acetyl-CoA flux away from acetate and toward mevalonate production, reducing acetate titers $88.4 \%$. Both PI.HMGR and PI.HMGS in hybrid pathways resulted in similar titers of mevalonate when compared to the yeast pathway. However, both exhibited reduced acetate levels suggesting an accumulation of redirected carbon in the pathway. Pathways with native P. indianae genes (Figure 7, light green genes), on the other hand, produced reduced levels of mevalonate, similar to what we observed previously $(<0.10 \mathrm{~g} / \mathrm{L})$. The native PI.atoB and PI.HMGS produced no mevalonate (data not shown) while the native PI.HMGR greatly reduced mevalonate production $(\sim 0.18 \mathrm{~g} / \mathrm{L})$ and led to higher accumulation of acetate $(\sim 3.0 \mathrm{~g} / \mathrm{L})$ compared to the yeast pathway (Figure 7, 1 unoptimized P. indianae gene). These results further demonstrate that genes from anaerobic fungi need to be codon optimized for both growth and mevalonate production in E. coli. Previously, individual genes from anaerobic fungi have been expressed and purified in E. coli after codon-optimization in order to be combined for a pretreatment cellulase cocktail for lignocellulose degradation [50]. However, this is the first demonstration of multiple genes being simultaneously expressed in the same host as is required for the mevalonate biosynthesis pathway. 


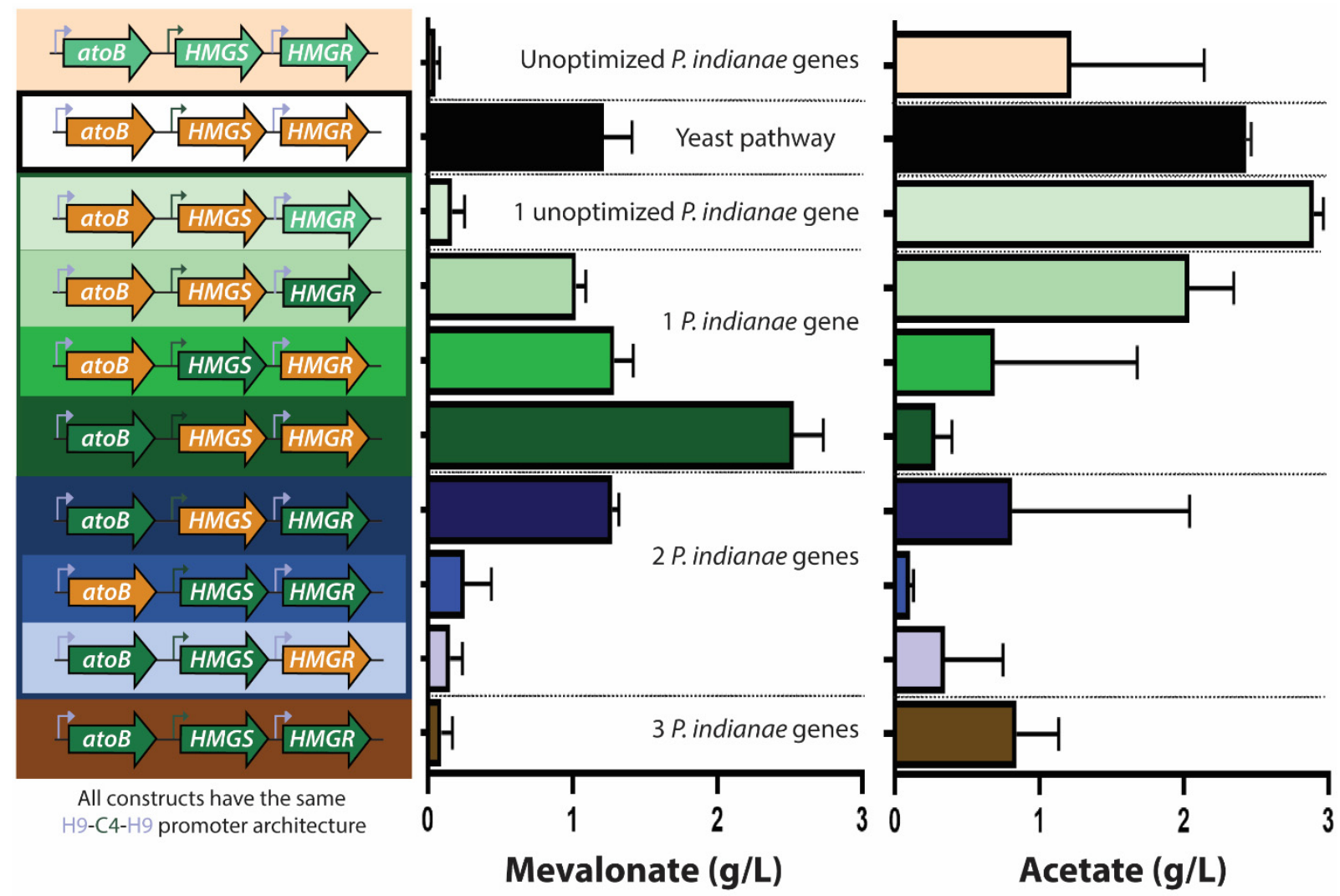

Figure 7. Mevalonate and acetate titers of original and hybrid mevalonate pathways. Pathway configuration (left), mevalonate production (middle), and acetate accumulation (right) from various mevalonate pathway hybrids containing individual genes from Martin et al. (orange), native $P$. indianae genes (light green), or $E$. coli-codon optimized P. indianae genes (dark green) after $20 \mathrm{~h}$ of culture. Green bars represent pathways with one PI homolog, blue bars and brown bars represent pathways with two and three PI homologs, respectively. All pathways are configured in the high-producing h9-promoter configuration. Errors bars represent standard deviation; $\mathrm{n}=3$ for all conditions.

Most hybrid constructs with two P. indianae genes (Figure 7, blue bars) saw a decrease in the amount of both acetate and mevalonate when compared to the parent one-P. indianaegene hybrid (Figure 7, green bars). Mevalonate produced by combining the first and last gene homologs (PI.atoB and PI.HMGR) with the SC.HMGS reached a level between the levels produced by either one-gene hybrid. Based on the lower acetate level of this two-gene hybrid, we suspect that SC.HMGS was hindering the overall flux of acetyl-CoA to mevalonate compared to other two two-gene hybrids containing PI.HMGS. The PI.atoBPI.HMGS-SC.HMGR pathway made very little mevalonate (less than $0.25 \mathrm{~g} / \mathrm{L}$ ), considering that these one-gene hybrids individually both produced more than $1 \mathrm{~g} / \mathrm{L}$. However, when we expressed this pathway on a smaller scale ( $5 \mathrm{~mL}$, Figure S3), production titers increased to $1.6 \mathrm{~g} / \mathrm{L}$. While the reason for lower mevalonate titers at this larger scale $(50 \mathrm{~mL})$ is unclear, it suggests there may be specific culturing conditions that might improve the performance of these genes. Moreover, the optimal promoter architecture for anaerobic fungal homologs may be distinct from that of the yeast pathway tested here (H9-C4-H9) [51].

Ultimately, we show that codon optimization is necessary to unlock the biosynthetic potential of low-GC anaerobic fungi mirroring similar developments in high-GC Streptomyces and low-GC Bacillus for elucidation of bioactive natural products [52,53], anaerobic fungal membrane transporters [6], and even the use of reporters in Staphylococcus [54]. While many parameters remain to be tuned to obtain the highest possible mevalonate titers from the genes for anaerobic fungi, we demonstrate the functionality and utility of these P. indianae genes here. In spite of their low expression (see Section 3.2), which stymie classical catalytic characterization studies (i.e., $\mathrm{k}_{\mathrm{cat}}$ and $\mathrm{K}_{m}$ determination), the superior performance of hybrid $P$. indianae pathways suggests improved enzyme kinetics of anaerobic 
fungal homologs over the canonical yeast variants. Compared to the previous batch titers in E.coli using genes from S. cerevisiae ( $\sim .4 \mathrm{~g} / \mathrm{L}$; [48]) or Enterococcus faecalis (3.1 g/L; [55]), our observed titers of $2.5 \mathrm{~g} / \mathrm{L}$ are a promising starting point for future studies that focus on optimizing promoter organization and culture condition. Optimization strategies with existing genes, such as fed-batch fermentations and metabolic engineering, have yielded mevalonate yields up to $30 \mathrm{~g} / \mathrm{L}$ [56]. These P. indianae sourced genes may prove to confer distinct advantages through anaerobic catalytic mechanisms that improve titers further [7]. In contrast to SC.HMGR, sequence homology analysis of PI.HMGR predicts that it uses NADH rather than NADPH as a cofactor in the synthesis of mevalonate (Figure 3A). While unvalidated, this putative cofactor preference may be beneficial for production in certain expression hosts and conditions.

\section{Conclusions}

In this study, we have validated the anaerobic fungal mevalonate pathway and revealed efficient homologs for heterologous expression in E. coli that synthesized mevalonate at levels comparable to or greater than known yeast homologs (up to $2.5 \mathrm{~g} / \mathrm{L}$ ). These active homologs also increased pathway efficiency by reducing carbon waste to acetate by almost $90 \%$ under the conditions tested. However, the intrinsic AT genomic bias of the source organism severely limits use of the native genes, which can inhibit heterologous host growth by up to $69 \%$ due to a preference for rare AT-rich codons. Sequence analysis is required to identify these biases as standard codon bias metrics, such as CAI, failed to predict the severe growth defects. Codon optimization, however, was an effective strategy to rescue growth and allow for gene evaluation of the P. indianae genes. Our work underscores the need for codon utilization analysis in harnessing genes from non-model organisms and lays the foundation for how additional biosynthetic pathways from anaerobic fungi can be expressed in model hosts like E. coli. Furthermore, codon optimization may be used as a strategy to revisit genes from anaerobic fungi that were previously abandoned after failed heterologous expression attempts. By overcoming these expression barriers, the repertoire of potentially valuable enzymes from anaerobic fungi can be fully realized.

Supplementary Materials: The following are available online at https:/ / www.mdpi.com/article/10 .3390/microorganisms9091986/s1, Tables S1-S3 - Codon Tables of P. indianae, E. coli, and S. cerevisiae, Figure S1-SDS-PAGE analysis of mevalonate homologs, Figure S2-Growth OD600 of $50 \mathrm{~mL}$ cultures containing various mevalonate pathways after $20 \mathrm{~h}$ of growth, Figure S3-Mevalonate and acetate titers of original and hybrid mevalonate pathways at $5 \mathrm{~mL}$ scale, Tables S4-S7-Strains, Oligos, Plasmids, and gene sequences used in this study.

Author Contributions: E.T.H.: Conceptualization, Formal analysis, Data curation, Investigation, Methodology, Project administration, Software, Supervision, Validation, Visualization; Roles/Writingoriginal draft. E.M.F.: Formal analysis, Data curation, Investigation. E.K.S.: Investigation. A.N.O.-V.: Investigation. J.A.E.: Conceptualization, Investigation, Data curation, Methodology, Resources, Validation, Writing-review \& editing. K.V.S.: Conceptualization, Funding acquisition, Project administration, Resources, Supervision, Writing-review \& editing. All authors have read and agreed to the published version of the manuscript.

Funding: This project was supported in part by the Office of Biological and Environmental Research through the DOE Office of Science Early Career Program, Contract No DE-SC0020117. This material is based upon work supported in part by the National Science Foundation under Grant No. CBET1836654.

Institutional Review Board Statement: Not applicable.

Informed Consent Statement: Not applicable.

Data Availability Statement: Not applicable.

Acknowledgments: We are grateful to J. Andrew Jones (Miami University) for his assistance with library construction. We would like to acknowledge Purdue's Office of Undergraduate Research, which provided an avenue for our undergraduate students to present and receive feedback on their 
work. Similarly, Purdue's Molecular Agriculture Summer Institute which supported undergraduate research in our lab and provided additional professional development opportunities. Appreciation is also given to the John Morgan who provided GC-MS analysis during the development of our quantitative methods. Finally, we thank Casey Hooker of the Solomon Lab for his never-ending maintenance and upkeep of the HPLC instrumentation.

Conflicts of Interest: The authors declare no conflict of interest. The funders had no role in the design of the study; in the collection, analyses, or interpretation of data; in the writing of the manuscript, or in the decision to publish the results.

\section{References}

1. Hillman, E.T.; Readnour, L.R.; Solomon, K.V. Exploiting the natural product potential of fungi with integrated-omics and synthetic biology approaches. Curr. Opin. Syst. Biol. 2017, 5, 50-56. [CrossRef]

2. $\quad$ Flad, V.; Young, D.; Seppälä, S.; Hooker, C.; Youssef, N.; Podmirseg, S.M.; Nagler, M.; Reilly, M.; Li, Y.; Fliegerová, K.; et al. The Biotechnological Potential of Anaerobic Gut Fungi. In Genetics and Biotechnology; Benz, J.P., Schipper, K., Eds.; Springer International Publishing: Cham, Switzerland, 2020; pp. 413-437, ISBN 978-3-030-49924-2.

3. Seppälä, S.; Wilken, S.E.; Knop, D.; Solomon, K.V.; O'Malley, M.A. The importance of sourcing enzymes from non-conventional fungi for metabolic engineering and biomass breakdown. Metab. Eng. 2017, 44, 45-59. [CrossRef]

4. Hooker, C.A.; Lee, K.Z.; Solomon, K.V. Leveraging anaerobic fungi for biotechnology. Curr. Opin. Biotechnol. 2019, 59, 103-110. [CrossRef]

5. Henske, J.K.; Wilken, S.E.; Solomon, K.V.; Smallwood, C.R.; Shutthanandan, V.; Evans, J.E.; Theodorou, M.K.; O’Malley, M.A. Metabolic characterization of anaerobic fungi provides a path forward for bioprocessing of crude lignocellulose. Biotechnol. Bioeng. 2018, 115, 874-884. [CrossRef]

6. Seppälä, S.; Yoo, J.I.; Yur, D.; O’Malley, M.A. Heterologous transporters from anaerobic fungi bolster fluoride tolerance in Saccharomyces cerevisiae. Metab. Eng. Commun. 2019, 9, e00091. [CrossRef] [PubMed]

7. Perli, T.; Vos, A.M.; Bouwknegt, J.; Dekker, W.J.C.; Wiersma, S.J.; Mooiman, C.; Ortiz-Merino, R.A.; Daran, J.-M.; Pronk, J.T. Identification of Oxygen-Independent Pathways for Pyridine Nucleotide and Coenzyme A Synthesis in Anaerobic Fungi by Expression of Candidate Genes in Yeast. MBio 2021, 12, e00967-21. [CrossRef] [PubMed]

8. Swift, C.; Louie, K.; Bowen, B.; Brewer, H.; Purvine, S.; Salamov, A.; Mondo, S.; Solomon, K.; Wright, A.; Northen, T.; et al. Anaerobic gut fungi are an untapped reservoir of natural products. Proc. Natl. Acad. Sci. USA 2021, 118, 1-10. [CrossRef]

9. Haitjema, C.H.; Gilmore, S.P.; Henske, J.K.; Solomon, K.V.; De Groot, R.; Kuo, A.; Mondo, S.; Salamov, A.A.; LaButti, K.; Zhao, Z.; et al. A Parts List for Fungal Cellulosomes Revealed by Comparative Genomics. Nat. Microbiol. 2017, 2, 17087. [CrossRef] [PubMed]

10. Russo, E. Special Report: The birth of biotechnology. Nature 2003, 421, 456-457. [CrossRef]

11. Chi, H.; Wang, X.; Shao, Y.; Qin, Y.; Deng, Z.; Wang, L.; Chen, S. Engineering and modification of microbial chassis for systems and synthetic biology. Synth. Syst. Biotechnol. 2019, 4, 25-33. [CrossRef] [PubMed]

12. Athey, J.; Alexaki, A.; Osipova, E.; Rostovtsev, A.; Santana-Quintero, L.V.; Katneni, U.; Simonyan, V.; Kimchi-Sarfaty, C. A new and updated resource for codon usage tables. BMC Bioinform. 2017, 18, 1-10. [CrossRef] [PubMed]

13. O'Malley, M.A.; Theodorou, M.K.; Kaiser, C.A. Evaluating Expression and Catalytic Activity of Anaerobic Fungal Fibroyltic Enzymes Native to Piromyces sp E2 in Saccharomyces cerevisiae. Environ. Sci. Technol. 2012, 31, 37-46. [CrossRef]

14. Bernaudat, F.; Frelet-Barrand, A.; Pochon, N.; Dementin, S.; Hivin, P.; Boutigny, S.; Rioux, J.B.; Salvi, D.; Seigneurin-Berny, D.; Richaud, P.; et al. Heterologous expression of membrane proteins: Choosing the appropriate host. PLoS ONE 2011, 6, e29191. [CrossRef]

15. Fernández, F.J.; Vega, M.C. Choose a Suitable Expression Host: A Survey of Available Protein Production Platforms. In Advanced Technologies for Protein Complex Production and Characterization; Vega, M.C., Ed.; Springer International Publishing: Cham, Switzerland, 2016; pp. 15-24, ISBN 978-3-319-27216-0.

16. Heneghan, M.N.; Yakasai, A.A.; Halo, L.M.; Song, Z.; Bailey, A.M.; Simpson, T.J.; Cox, R.J.; Lazarus, C.M. First heterologous reconstruction of a complete functional fungal biosynthetic multigene cluster. ChemBioChem 2010, 11, 1508-1512. [CrossRef] [PubMed]

17. Saye, L.M.G.; Navaratna, T.A.; Chong, J.P.J.; O'malley, M.A.; Theodorou, M.K.; Reilly, M. The anaerobic fungi: Challenges and opportunities for industrial lignocellulosic biofuel production. Microorganisms 2021, 9, 694. [CrossRef] [PubMed]

18. Wilken, S.E.; Seppälä, S.; Lankiewicz, T.S.; Saxena, M.; Henske, J.K.; Salamov, A.A.; Grigoriev, I.V.; O’Malley, M.A. Genomic and proteomic biases inform metabolic engineering strategies for anaerobic fungi. Metab. Eng. Commun. 2020, 10, 1-10. [CrossRef]

19. Hooker, C.A.; Hillman, E.T.; Overton, J.C.; Ortiz-Velez, A.; Schacht, M.; Hunnicutt, A.; Mosier, N.S.; Solomon, K.V. Hydrolysis of untreated lignocellulosic feedstock is independent of S-lignin composition in newly classified anaerobic fungal isolate, Piromyces sp. UH3-1. Biotechnol. Biofuels 2018, 11, 1-14. [CrossRef]

20. Hillman, E.T.; Li, M.; Hooker, C.A.; Englaender, J.A.; Wheeldon, I.; Solomon, K. V Hydrolysis of lignocellulose by anaerobic fungi produces free sugars and organic acids for two-stage fine chemical production with Kluyveromyces marxianus. Biotechnol. Prog. 2021, e3172. [CrossRef] 
21. Maloy, S.R. Genetic Analysis of Pathogenic Bacteria: A Laboratory Manual; Cold Spring Harbor Laboratory Press: Plainview, NY, USA, 1996; ISBN 0879694521.

22. Wood, V.; Gwilliam, R.; Rajandream, M.A.; Lyne, M.; Lyne, R.; Stewart, A.; Sgouros, J.; Peat, N.; Hayles, J.; Baker, S.; et al. The genome sequence of Schizosaccharomyces pombe. Nature 2003, 421, 871-880. [CrossRef]

23. Guimaraes, J.C.; Mittal, N.; Gnann, A.; Jedlinski, D.; Riba, A.; Buczak, K.; Schmidt, A.; Zavolan, M. A rare codon-based translational program of cell proliferation. Genome Biol. 2020, 21, 1-20. [CrossRef]

24. Nordberg, H.; Cantor, M.; Dusheyko, S.; Hua, S.; Poliakov, A.; Shabalov, I.; Smirnova, T.; Grigoriev, I.V.; Dubchak, I. The genome portal of the Department of Energy Joint Genome Institute: 2014 updates. Nucleic Acids Res. 2014, 42, 26-31. [CrossRef] [PubMed]

25. Camacho, C.; Coulouris, G.; Avagyan, V.; Ma, N.; Papadopoulos, J.; Bealer, K.; Madden, T.L. BLAST+: Architecture and applications. BMC Bioinform. 2009, 10, 421. [CrossRef] [PubMed]

26. Kumar, S.; Stecher, G.; Tamura, K. MEGA7: Molecular Evolutionary Genetics Analysis version 7.0 for bigger datasets. Mol. Biol. Evol. 2016, 33, 1870-1874. [CrossRef]

27. Xu, P.; Vansiri, A.; Bhan, N.; Koffas, M.A.G. EPathBrick: A synthetic biology platform for engineering metabolic pathways in $E$. coli. ACS Synth. Biol. 2012, 1, 256-266. [CrossRef]

28. Martin, V.J.J.; Piteral, D.J.; Withers, S.T.; Newman, J.D.; Keasling, J.D. Engineering a mevalonate pathway in Escherichia coli for production of terpenoids. Nat. Biotechnol. 2003, 21, 796-802. [CrossRef] [PubMed]

29. Cock, P.J.A.; Antao, T.; Chang, J.T.; Chapman, B.A.; Cox, C.J.; Dalke, A.; Friedberg, I.; Hamelryck, T.; Kauff, F.; Wilczynski, B.; et al. Biopython: Freely available Python tools for computational molecular biology and bioinformatics. Bioinformatics 2009, 25, 1422-1423. [CrossRef]

30. Li, S.; Jendresen, C.B.; Nielsen, A.T. Increasing production yield of tyrosine and mevalonate through inhibition of biomass formation. Process Biochem. 2016, 51, 1992-2000. [CrossRef]

31. Jansen, R.; Bussemaker, H.J.; Gerstein, M. Revisiting the codon adaptation index from a whole-genome perspective: Analyzing the relationship between gene expression and codon occurrence in yeast using a variety of models. Nucleic Acids Res. 2003, 31, 2242-2251. [CrossRef]

32. Lee, B.D. Python Implementation of Codon Adaptation Index. J. Open Source Softw. 2018, 30, 356-362. [CrossRef]

33. Quax, T.E.F.; Claassens, N.J.; Söll, D.; van der Oost, J. Codon Bias as a Means to Fine-Tune Gene Expression. Mol. Cell 2015, 59, 149-161. [CrossRef]

34. Henry, I.; Sharp, P.M. Predicting gene expression level from codon usage bias. Mol. Biol. Evol. 2007, 24, 10-12. [CrossRef] [PubMed]

35. Khomtchouk, B.B.; Nonner, W. Gaussian-distributed codon frequencies of genomes. G3 Genes Genomes Genet. 2019, 9, 1449-1456. [CrossRef] [PubMed]

36. Chaney, J.L.; Steele, A.; Carmichael, R.; Rodriguez, A.; Specht, A.T.; Ngo, K.; Li, J.; Emrich, S.; Clark, P.L. Widespread positionspecific conservation of synonymous rare codons within coding sequences. PLoS Comput. Biol. 2017, 13, 1-19. [CrossRef] [PubMed]

37. Mittal, P.; Brindle, J.; Stephen, J.; Plotkin, J.B.; Kudla, G. Codon usage influences fitness through RNA toxicity. Proc. Natl. Acad. Sci. USA 2018, 115, 8639-8644. [CrossRef]

38. Dong, H.; Nilsson, L.; Kurland, C.G. Co-variation of tRNA Abundance and Codon Usage inEscherichia coliat Different Growth Rates. J. Mol. Biol. 1996, 260, 649-663. [CrossRef]

39. Berg, O.G.; Kurland, C.G. Growth rate-optimised tRNA abundance and codon usage. J. Mol. Biol. 1997, 270, 544-550. [CrossRef]

40. Boël, G.; Letso, R.; Neely, H.; Price, W.N.; Wong, K.H.; Su, M.; Luff, J.D.; Valecha, M.; Everett, J.K.; Acton, T.B.; et al. Codon influence on protein expression in E. coli correlates with mRNA levels. Nature 2016, 529, 358-363. [CrossRef] [PubMed]

41. Gong, M.; Gong, F.; Yanofsky, C. Overexpression of tnaC of Escherichia coli inhibits growth by depleting tRNA2Pro availability. J. Bacteriol. 2006, 188, 1892-1898. [CrossRef] [PubMed]

42. Liao, P.; Hemmerlin, A.; Bach, T.J.; Chye, M.L. The potential of the mevalonate pathway for enhanced isoprenoid production. Biotechnol. Adv. 2016, 34, 697-713. [CrossRef]

43. Frumkin, I.; Lajoie, M.J.; Gregg, C.J.; Hornung, G.; Church, G.M.; Pilpel, Y. Codon usage of highly expressed genes affects proteome-wide translation efficiency. Proc. Natl. Acad. Sci. USA 2018, 115, E4940-E4949. [CrossRef]

44. McDonald, M.J.; Chou, C.H.; Swamy, K.B.S.; Huang, H.D.; Leu, J.Y. The evolutionary dynamics of tRNA-gene copy number and codon-use in E. coli. BMC Evol. Biol. 2015, 15, 1-10. [CrossRef]

45. Angov, E.; Hillier, C.J.; Kincaid, R.L.; Lyon, J.A. Heterologous protein expression is enhanced by harmonizing the codon usage frequencies of the target gene with those of the expression host. PLoS ONE 2008, 3, e2189. [CrossRef] [PubMed]

46. Kizer, L.; Pitera, D.J.; Pfleger, B.F.; Keasling, J.D. Application of functional genomics to pathway optimization for increased isoprenoid production. Appl. Environ. Microbiol. 2008, 74, 3229-3241. [CrossRef] [PubMed]

47. Krogh, A.; Larsson, B.; Von Heijne, G.; Sonnhammer, E.L.L. Predicting transmembrane protein topology with a hidden Markov model: Application to complete genomes. J. Mol. Biol. 2001, 305, 567-580. [CrossRef]

48. Ma, S.M.; Garcia, D.E.; Redding-Johanson, A.M.; Friedland, G.D.; Chan, R.; Batth, T.S.; Haliburton, J.R.; Chivian, D.; Keasling, J.D.; Petzold, C.J.; et al. Optimization of a heterologous mevalonate pathway through the use of variant HMG-CoA reductases. Metab. Eng. 2011, 13, 588-597. [CrossRef] [PubMed] 
49. Jones, J.A.; Vernacchio, V.R.; Lachance, D.M.; Lebovich, M.; Fu, L.; Shirke, A.N.; Schultz, V.L.; Cress, B.; Linhardt, R.J.; Koffas, M.A.G. EPathOptimize: A combinatorial approach for transcriptional balancing of metabolic pathways. Sci. Rep. 2015, 5, 1-10. [CrossRef]

50. Morrison, J.M.; Elshahed, M.S.; Youssef, N.H. Defined enzyme cocktail from the anaerobic fungus Orpinomyces sp. Strain C1A effectively releases sugars from pretreated corn stover and switchgrass. Sci. Rep. 2016, 6, 1-12. [CrossRef] [PubMed]

51. Jones, J.A.; Toparlak, T.D.; Koffas, M.A.G. Metabolic pathway balancing and its role in the production of biofuels and chemicals. Curr. Opin. Biotechnol. 2015, 33, 52-59. [CrossRef] [PubMed]

52. Zhang, J.J.; Tang, X.; Moore, B.S. Genetic platforms for heterologous expression of microbial natural products. Nat. Prod. Rep. 2019, 36, 1313-1332. [CrossRef]

53. Li, Y.; Li, Z.; Yamanaka, K.; Xu, Y.; Zhang, W.; Vlamakis, H.; Kolter, R.; Moore, B.S.; Qian, P.Y. Directed natural product biosynthesis gene cluster capture and expression in the model bacterium Bacillus subtilis. Sci. Rep. 2015, 5, 1-7. [CrossRef]

54. Sastalla, I.; Chim, K.; Cheung, G.Y.C.; Pomerantsev, A.P.; Leppla, S.H. Codon-optimized fluorescent proteins designed for expression in low-GC gram-positive bacteria. Appl. Environ. Microbiol. 2009, 75, 2099-2110. [CrossRef] [PubMed]

55. Yang, J.; Xian, M.; Su, S.; Zhao, G.; Nie, Q.; Jiang, X.; Zheng, Y.; Liu, W. Enhancing production of bio-isoprene using hybrid MVA pathway and isoprene synthase in E. coli. PLoS ONE 2012, 7, e33509. [CrossRef] [PubMed]

56. Wang, J.; Niyompanich, S.; Tai, Y.-S.; Wang, J.; Bai, W.; Mahida, P.; Gao, T.; Zhang, K. Engineering of a highly efficient Escherichia coli strain for mevalonate fermentation through chromosomal integration. Appl. Environ. Microbiol. 2016, 82, 7176-7184. [CrossRef] [PubMed] 